UDK 528.389

\title{
GEODINAMINIŲ ŽEMĖS PLUTOS IৃTAMPŲ POKYČIAI IGNALINOS ATOMINĖS ELEKTRINĖS REGIONE
}

\author{
Algimantas Zakarevičius, Arminas Stanionis \\ Geodezijos ir kadastro katedra, Vilniaus Gedimino technikos universitetas, \\ Saulètekio al.11,LT-10223 Vilnius-40,Lietuva, el.paštas: gkk@ap.vtu.lt
}

Lteikta 200406 18; priimta 20040928

\begin{abstract}
Santrauka. Tyrimas atliktas siekiant pritaikyti atvirkštinį Huko fizinį dėsnį horizontaliujų Žemės plutos deformacijų bei geodinaminių įtampų sąsajoms aprašyti, teoriškai pagrịsta tenzorinè įtampų i̇vertinimo metodika bei atlikti eksperimentiniai žemès plutos itampu Ignalinos atominès elektrinés regiono teritorijoje skaičiavimai. Gauti nauji geodinaminiu ittampų pokyčių duomenys, kurie akivaizdžiai yra susiję su teritorijos tektonine sandara. Išanalizavus skaičiavimo pagal geodezinių matavimų duomenis rezultatus ir apibendrinus, nustatytas tektoninis aktyvumas Drūkšiu grabeno aplinkoje. Daroma išvada, kad atvirkštinis Huko dėsnis, nusakant horizontaliujų Žemès plutos judesių bei geodinaminių ịtampų sąsajas, gali būti taikomas praktiškai bei įvertinant geodinaminiu įtampų pokyčių dèsningumus.
\end{abstract}

Raktažodžiai: GPS, geodinaminiai procesai, tektoninės įtampos, Žemės plutos deformacijos.

\section{Ivadas}

Horizontaliosioms Žemès plutos deformacijoms Ignalinos atominès elektrinès regione nustatyti pagal gruntinių punktų koordinačių pokyčius taikytas naujas deformaciju parametru ivertinimo metodas, darant prielaidą, kad horizontaliosios deformacijos pagal pobūdi yra vienalytès bei izotropinès. Apskaičiuotos svarbiausiosios deformacijos: didžiausiasis bei mažiausiasis santykinis pailgèjimai bei jų kryptys, baigtinio elemento santykinè dilatacija, linijinès bei šlyties deformacijos.

Teoriškai pagrịsta geodinaminių Žemès plutos itampu tenzorinè skaičiavimo metodika. Taikant fizinę sąsają tarp horizontaliujų deformacijų bei itampu gauti nauji eksperimentinio tyrimo rezultatai, kuriais remiantis ivvertinti Ignalinos atominès elektrinès regiono tektoninès sandaros ypatumai. Nustatyta, kad teritorija geodinaminiu požiūriu tebèra aktyvi ir dabar.

Pagal apibrěžtas Žemès plutos geodinaminių itampu kitimo tendencijas galima detaliau ir tiksliau nustatyti dabartini tektoninių struktūrų aktyvumą, nes atsižvelgiama į teritorijos fizines bei mechanines savybes. Platesnès gautų rezultatų interpretavimo galimybès geotektoniniu požiūriu, nes gautieji skaičiavimo duomenys išreiškiami ne santykiniu dydžiu - kaip horizontaliujų deformaciju parametrai bei ju iverčiai, o jègos vienetais, tenkančiais ploto vienetui.

Geodinaminių itampų laukų charakteristikos praktiniu požiūriu yra labai svarbios ir aktualios prognozuojant tektoninių lūžių seismiškumą.

\section{Horizontaliųjų deformacijų skaičiavimo metodika}

Horizontaliosios Žemès plutos deformacijos nustatomos pagal geodezinių tinklų kartotinių matavimų duomenis. Pagal juos galima apibūdinti horizontaliujuc Žemès plutos judesių, vykusių per laiko intervalą tarp kartotinių matavimų, savybes. Plačiai taikomas horizontaliujų Žemès plutos judesių nustatymo būdas identiškų punktų koordinačių, apskaičiuotų pagal skirtingu laiku atliktų matavimų rezultatus, palyginimas [1-7].

Turint geodezinio tinklo punktų plokštumos koordinačių horizontaliuosius poslinkius, Žemès plutos homogeninius deformaciju parametrus baigtiniame elemente (trikampyje) galima apskaičiuoti pagal [8] darbe pateiktą metodiką. Žemès plutos horizontaliąsias deformacijas galima nustatyti taikant tašku poslinkio vienalytėje bei izotropinejje dvimatèje erdvèje modeli [8]:

$$
\Delta X=A \cdot E,
$$

čia

$$
\Delta X=\left[\begin{array}{c}
\Delta x_{1} \\
\Delta x_{2} \\
\Delta x_{3} \\
\Delta y_{1} \\
\Delta y_{2} \\
\Delta y_{3}
\end{array}\right],
$$

$$
A=\left[\begin{array}{cccccc}
1 & x_{S_{1}} & y_{S_{1}} & 0 & 0 & 0 \\
1 & x_{S_{2}} & y_{S_{2}} & 0 & 0 & 0 \\
1 & x_{S_{3}} & y_{S_{3}} & 0 & 0 & 0 \\
0 & 0 & 0 & 1 & x_{S_{1}} & y_{S_{1}} \\
0 & 0 & 0 & 1 & x_{S_{2}} & y_{S_{2}} \\
0 & 0 & 0 & 1 & x_{S_{3}} & y_{S_{3}}
\end{array}\right],
$$




$$
E=\left[\begin{array}{c}
\alpha_{x} \\
\varepsilon_{x x} \\
\frac{1}{2} \cdot \varepsilon_{x y}-\omega \\
\alpha_{y} \\
\frac{1}{2} \cdot \varepsilon_{x y}+\omega \\
\varepsilon_{y y}
\end{array}\right],
$$

čia $\Delta X-$ punktų plokštumos koordinačiu poslinkių vektorius, $A$ - punktų plokštumos koordinačiu nuokrypių nuo jų vidurkio matrica, $E-$ horizontaliujuc Žemès plutos deformaciju parametrų vektorius; $\Delta x_{i}=x_{i}^{\prime}-x_{i}, \Delta y_{i}=y_{i}^{\prime}-y_{i}, x_{i}, y_{i}$ - pirmojo matavimo punktų plokštumos koordinatès, $x_{i}{ }_{i}, y^{\prime}{ }_{i}-$ antrojo matavimo punktų plokštumos koordinatès, $i=1,2, \ldots n-$ punktu numeriai; $x_{S_{i}}, y_{S_{i}}-$ geodezinio tinklo punktu plokštumos koordinačiu nuokrypiai nuo jų vidurkio, $\alpha_{x}, \alpha_{y}$ - baigtinio elemento poslinkiai abscisiu ir ordinačių kryptimis, $\varepsilon_{x x}, \varepsilon_{y y}-$ santykinès linijinès deformacijos, $\varepsilon_{x y}$ - santykinès šlyties deformacijos; $\omega-$ baigtinio elemento posūkis.

Horizontaliujų Žemès plutos deformacijų parametru rezultatų vektorius apskaičiuojamas [8]:

$$
E=A^{-1} \cdot \Delta X
$$

Tačiau pagal [8] darbe pateiktas $(2,3,5)$ formules horizontaliujų Žemés plutos judesių deformaciju parametrus galima apskaičiuoti baigtinio elemento plotui, kuris šiuo atveju yra trikampis.

Sudarant baigtinių elementų tinklą trikampiais, ne visuomet galima tiksliai ir detaliai atsižvelgti i tiriamojo regiono tektoninès sandaros savybes bei ypatumus, jei tai nebuvo atlikta projektuojant ir irengiant geodezinio tinklo gruntinius punktus. Tada baigtinių elementu tinklas modeliuojamas itraukiant ir kitas daugiakampes geometrines figūras arba blokines struktūras.

Tiriant Žemès plutos horizontaliuosius judesius bei atliekant dabartinių geodinaminių procesų analizę - [8] darbe pateiktą motodiką reikètu išplèsti, t. y. pritaikyti geodezinio tinklo, sudaryto iš blokinių struktūrų ar jų fragmentu, horizontaliujų deformacijų parametrams skaičiuoti ir įvertinti.

Blokinès struktūros punktų plokštumos koordinačių poslinkių vektorius:

$$
\Delta X=\left[\begin{array}{c}
\Delta x_{1} \\
\vdots \\
\Delta x_{i} \\
\Delta y_{1} \\
\vdots \\
\Delta y_{i}
\end{array}\right]
$$

Punktų plokštumos koordinačių nuokrypių nuo ju vidurkio matrica:

$$
A=\left[\begin{array}{cccccc}
1 & x_{S_{1}} & y_{S_{1}} & 0 & 0 & 0 \\
\vdots & \vdots & \vdots & \vdots & \vdots & \vdots \\
1 & x_{S_{i}} & y_{S_{i}} & 0 & 0 & 0 \\
0 & 0 & 0 & 1 & x_{S_{1}} & y_{S_{1}} \\
\vdots & \vdots & \vdots & \vdots & \vdots & \vdots \\
0 & 0 & 0 & 1 & x_{S_{i}} & y_{S_{i}}
\end{array}\right] .
$$

Horizontaliujų Žemès plutos deformacijų parametru vektorius įvertinamas mažiausiujų kvadratų metodu:

$$
E=\left(A^{T} \cdot A\right)^{-1} \cdot A^{T} \cdot \Delta X
$$

Baigtinio elemento santykinè dilatacija:

$$
\Delta=\varepsilon_{x x}+\varepsilon_{y y} .
$$

Svarbiausios horizontaliosios deformacijos didžiausiasis bei mažiausiasis santykinis pailgejjimas:

$$
\begin{aligned}
& \varepsilon_{1}=\frac{1}{2} \cdot(\Delta+\gamma), \\
& \varepsilon_{2}=\frac{1}{2} \cdot(\Delta-\gamma),
\end{aligned}
$$

čia

$$
\gamma=\left\{\left(\varepsilon_{x x}-\varepsilon_{y y}\right)^{2}+\varepsilon_{x y}^{2}\right\}^{\frac{1}{2}} .
$$

Didžiausiojo santykinio pailgejjimo kryptis

$$
\varphi=\frac{1}{2} \operatorname{arctg}\left(\frac{\varepsilon_{x y}}{\varepsilon_{y y}-\varepsilon_{x x}}\right) .
$$

Nustatytos Žemès plutos judesių horizontaliosios deformacijos siejamos su baigtinio elemento svorio centru.

\section{Geodinaminių ittampų ir horizontaliųjų deformacijų sąsajos}

Turint apskaičiuotas horizontaliąsias santykines linijines bei šlyties deformacijas, gali būti ịvertinta geodinaminių ittampu pokyčiai, t. y. nustatyti itampu prieaugiai per tam tikrą laiko tarpa. 
Geodinaminėms itampoms

modeliuoti horizontaliojoje plokštumoje gali būti pritaikytas atvirkštinis Huko dèsnis, įtempimus išreiškus deformacijomis $[9,10]$ :

$$
\left\{\begin{array}{l}
\sigma_{x x}=\frac{E}{1-v^{2}} \cdot\left(\varepsilon_{x x}+v \cdot \varepsilon_{y y}\right), \\
\sigma_{y y}=\frac{E}{1-v^{2}} \cdot\left(\varepsilon_{y y}+v \cdot \varepsilon_{x x}\right), \\
\sigma_{x y}=G \cdot \varepsilon_{x y}=\frac{E}{2 \cdot(1+v)} \cdot \varepsilon_{x y},
\end{array},\right.
$$

čia $G$ - šlyties modulis, $E$ - tamprumo modulis $\left(7 \cdot 10^{10} \frac{\mathrm{N}}{\mathrm{m}^{2}}\right), v-$ Puasono koeficientas $(0,25), \sigma_{x x}$, $\sigma_{y y}-$ normaliniai itempimai, $\sigma_{x y}-$ tangentiniai itempimai.

Fizines priklausomybes (14) galima užrašyti matricine forma [11-13]:

$$
\sigma=K \cdot \boldsymbol{\varepsilon}
$$

čia

$$
\sigma=\left[\begin{array}{lll}
\sigma_{x x} & \sigma_{y y} & \sigma_{x y}
\end{array}\right]^{T}
$$

$$
\begin{gathered}
K=\frac{E}{1-v^{2}} \cdot\left[\begin{array}{ccc}
1 & v & 0 \\
v & 1 & 0 \\
0 & 0 & \frac{1-v}{2}
\end{array}\right], \\
\boldsymbol{\varepsilon}=\left[\begin{array}{lll}
\varepsilon_{x x} & \varepsilon_{y y} & \varepsilon_{x y}
\end{array}\right]^{T},
\end{gathered}
$$

čia $\boldsymbol{\sigma}$-geodinaminių įtampų vektorius, $\boldsymbol{\varepsilon}$ - horizontaliujuc Žemès plutos deformaciju vektorius, $K$ - standumo matrica.

Pagal tangentinių itempimų dualumo dèsni [9] $\sigma_{x y}=\sigma_{y x}$. Tada geodinaminių įtempimų horizontaliojoje plokštumoje būvis nusakomas simetriniu ittempimu tenzoriumi [9-13]:

$$
\tilde{\sigma}=\left[\begin{array}{cc}
\sigma_{x x} & \sigma_{x y} \\
\sigma_{x y} & \sigma_{y y}
\end{array}\right]
$$

Antrojo rango itempimų tenzorius $\tilde{\sigma}$ yra invariantinis koordinačių sistemos atžvilgiu, t. y. nepriklauso nuo koordinačių sistemos parinkimo.

\section{Horizontaliųjų Žemès plutos deformacijų ir geodinaminių ịtampų skačiavimo rezultatai}

Tyrimams atlikti pasirinktas Ignalinos atominès elektrinès geodinaminis poligonas (1 pav.), nes šioje

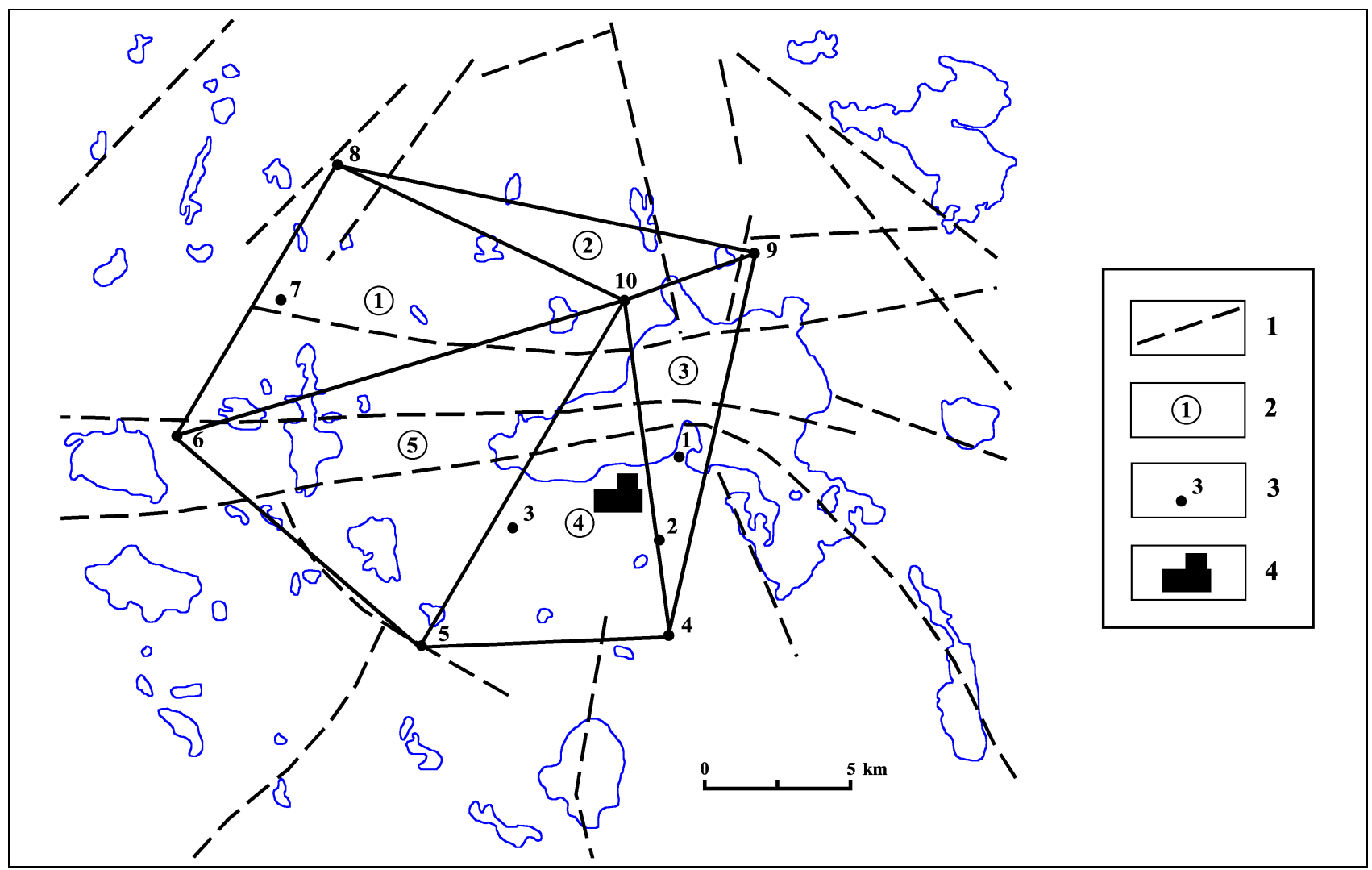

1 pav. Tektoninių lūžių išsidèstymo ir baigtinių elementų tinklo Ignalinos atominės elektrinès rajono teritorijoje schema: 1 tektoniniai lūžiai (sudarè P. Suveizdis), 2 - trikampio numeris, 3 - GPS punktas, 4 - Ignalinos atominè elektrinè

Fig 1. The location scheme of the tectonic breaks and network of the finite elements at the Ignalina Nuclear Power Plant: 1 - tectonic breaks (according to P. Suveizdis), 2 - number of triangles, 3 - GPS points, 4 - Ignalina NPP 
1 lentelè. Deformacijų parametrai

Table 1. Parameters of deformations

\begin{tabular}{|c|c|c|c|c|c|c|c|}
\hline Trikampio Nr. & $\varepsilon_{1} \cdot 10^{-6}$ & $\varepsilon_{2} \cdot 10^{-6}$ & $\Delta \cdot 10^{-6}$ & $\varphi^{\circ}$ & $\varepsilon_{x x} \cdot 10^{-6}$ & $\varepsilon_{y y} \cdot 10^{-6}$ & $\varepsilon_{x y} \cdot 10^{-6}$ \\
\hline 1 & $-0,269$ & $-1,194$ & $-1,463$ & 3,381 & $-1,191$ & $-0,272$ & 0,109 \\
\hline 2 & 0,284 & $-2,430$ & $-2,146$ & 6,890 & $-2,391$ & 0,245 & 0,647 \\
\hline 3 & 0,243 & $-0,511$ & $-0,268$ & $-1,343$ & $-0,511$ & 0,243 & $-0,035$ \\
\hline 4 & $-0,318$ & $-0,769$ & $-1,086$ & $-43,812$ & $-0,553$ & $-0,534$ & $-0,450$ \\
\hline 5 & $-0,277$ & $-1,850$ & $-2,127$ & 26,264 & $-1,542$ & $-0,585$ & 1,248 \\
\hline
\end{tabular}

2 lentelè. Geodinaminių itempimų prieaugiai

Table 2. Increments of geodynamic stresses

\begin{tabular}{|c|c|c|c|}
\hline $\begin{array}{c}\text { Trikampio } \\
\text { Nr. }\end{array}$ & $\sigma_{x x}, \mathrm{MPa}$ & $\sigma_{y y}, \mathrm{MPa}$ & $\sigma_{x y}, \mathrm{MPa}$ \\
\hline 1 & $-0,094$ & $-0,043$ & 0,003 \\
\hline 2 & $-0,174$ & $-0,026$ & 0,018 \\
\hline 3 & $-0,034$ & 0,009 & $-0,001$ \\
\hline 4 & $-0,051$ & $-0,050$ & $-0,013$ \\
\hline 5 & $-0,126$ & $-0,072$ & 0,035 \\
\hline
\end{tabular}

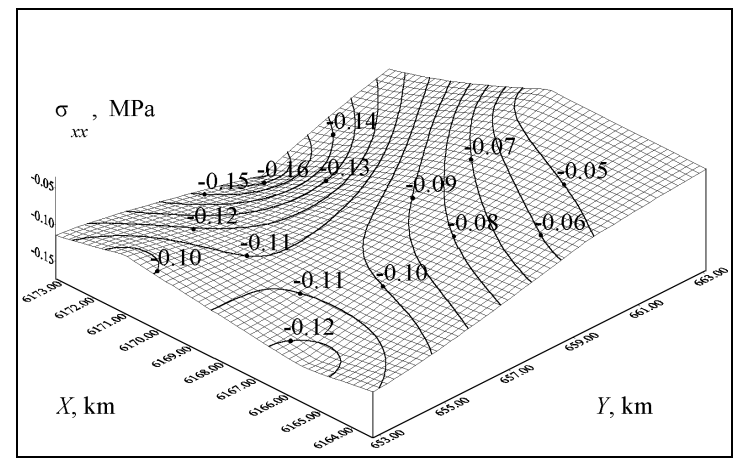

2 pav. $\sigma_{x x}$ itempimų izograma

Fig 2. Isogram of $\sigma_{x x}$ stresses

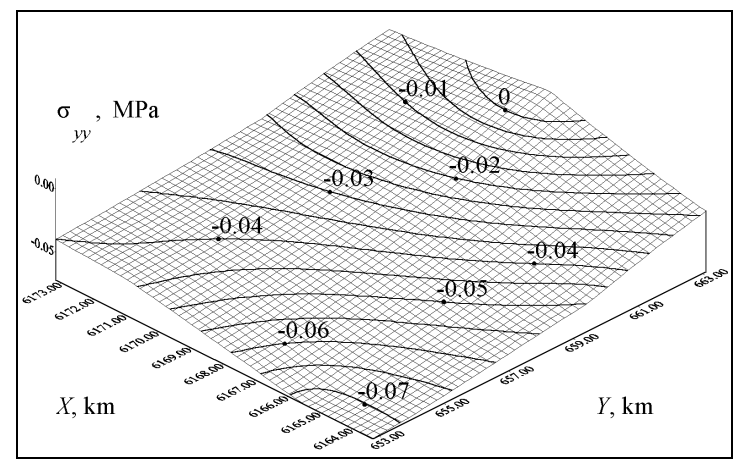

3 pav. $\sigma_{y y}$ itempimų izograma

Fig 3. Isogram of $\sigma_{y y}$ stresses

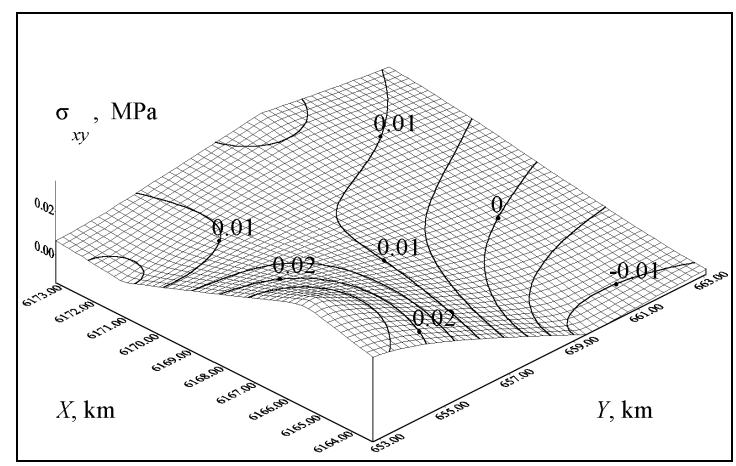

4 pav. $\sigma_{x y}$ itempimų izograma

Fig 4. Isogram of $\sigma_{x y}$ stresses teritorijoje tektoninè sandara sudètinga - kristalinis pamatas suskilęs nevienodo dydžio blokais. Dèl pagrindinių lūžių sistemų - submeridianinès ir platuminès - susidare daug subregioninių struktūrų bei platuminès krypties Drūkšių grabenas [14, 15].

Šiam regionui būdingos ir labai ryškios magnetinio lauko anomalijos: fiksuotas Drūkšių $\Delta T$ anomalijų plotas, jame itin išsiskiria grandinè anomaliju, kurių maksimalioji reikšmè - 1350 nT [14].

Taikant pateiktą metodiką, pagal (1-13) formules apskaičiuoti penkių geodinaminio poligono trikampių horizontaliujų deformacijų parametrai. Išanalizavus gautuosius rezultatus bei palyginus ( 1 lent.) su ankstesniujų tyrimų duomenimis $[16,17]$, daroma išvada, kad pasiūlytoji metodika gali būti taikoma įvertinant horizontaliąsias Žemès plutos judesių deformacijas.

Pagal geodezinių matavimu duomenis nèra galimybès nustatyti absoliučiujų Žemès plutos deformacijų rodiklių nuo deformacijų atsiradimo pradžios. Tegalima nustatyti tik deformacijų prieaugi (pokyti) per tam tikrą laiko tarpą nuo pradinių iki kartotinių matavimų. Todèl, remiantis geodezinių matavimu rezultatais ir funkcine deformaciju bei geodinaminių ịtampu priklausomybe, galima apskaičiuoti geodinaminiu ittampų prieaugius per laikotarpi tarp kartotinių matavimų. Pagal (15-18) formules įvertinti geodinaminiu itampu pokyčiai (2 lent.): apskaičiuoti normalinių bei tangentinių itempimu prieaugiai, ju pokyčiai pavaizduoti 2-4 paveiksluose. Pagal modeliavimo analizès rezultatus Ignalinos atominès elektrinès rajone pastebimi tam tikri Žemès plutos ittampu prieaugių pasiskirstymo dèsningumai. Jie susiję su teritorijos tektonine sandara [15] ir geofiziniais laukais [18].

Remiantis tyrimų duomenų analizès rezultatais galima daryti preliminarias išvadas, kad regioniniu struktūrų, Latvijos balno bei Mozūrijos-Baltarusijos anteklizès sandūros zona yra aktyvi ir dabar, nes yra nustatytas tangentinių itempimu mažejjimo pokytis, teigiamo ženklo itempimu prieaugiai Drūkšiu grabeno aplinkoje igyja neigiamas reikšmes (4 pav.), t. y. vyksta Žemès plutos bloko grimzdimas.

\section{Išvados}

1. Nustatant horizontaliujų Žemès plutos deformacijų bei geodinaminių itampų tarpusavio sąsajas bei kaitos dèsningumus gali būti taikoma invariantiška koordinačiu sistemos atžvilgiu tenzorinès analizès metodika. Išreiškus ittempimus deformacijomis, pagal atvirkštini Huko dèsni gauti nauji duomenys geodinaminių įtampų prieaugiai. 
2. Taikant siūlomą plokštuminių itampų i̇vertinimo metodiką galima nustatyti Žemès plutoje vykstančių dabartinių tektoninių bei lokaliujų judesių geodinamines tendencijas.

3. Atlikus eksperimentinio skaičiavimo pagal geodezinių matavimų duomenis rezultatų analizę nustatyta, kad geodinaminiu itampu pokyčiai yra susiję su Ignalinos atominès elektrinès regiono tektonine sandara. Pastebimas regioninių struktūrų (Latvijos balno bei Mozūrijos-Baltarusijos anteklizès) tektoninis aktyvumas Drūkšiu grabeno aplinkoje.

4. Ignalinos atominès elektrinès regione ívertinti geodinaminių Žemès plutos ịtampų pokyčiai, nustatyti itampu kitimo tarp kartotinių matavimu prieaugiai: normalinių itempimų $\sigma_{x x}$ prieaugių kitimo ribos - nuo $-0,034 \mathrm{MPa}$ iki -0,174 MPa; $\sigma_{y y}$ kinta nuo 0,009 $\mathrm{MPa}$ iki -0,072 MPa; tangentinių itempimu prieaugiai - nuo $0,035 \mathrm{MPa}$ iki $-0,013 \mathrm{MPa}$. Iš gautujų rezultatų matyti, kad teritorijoje vyksta akivaizdi geodinaminiu itampu kaita.

\section{Literatūra}

1. Zakarevičius, A. Investigation of the recent geodynamic processes in the territory of Lithuania (Dabartiniu geodinaminiu procesu Lietuvos teritorijoje tyrimas). Vilnius: Technika, 2003. 195 p. (in Lithuanian).

2. Zakarevičius, A. Analysis of deformations of zero order GPS network (Nulinès klasės GPS tinklo deformaciju analizè). Geodesy and Cartography (Geodezija ir kartografija), No 1(23). Vilnius: Technika, 1996, p. 53-61 (in Lithuanian).

3. Vaníček, P.; Krakiwsky, E. J. Geodesy: The concepts. $2^{\text {nd }}$ rev. ed. North-Holland, Amsterdam, 1986. 697 p.

4. Vaníček, P.; Craymer, M. R.; Krakiwsky, E. J. Robustness analysis of geodetic horizontal networks. Journal of geodesy, Vol 75, No 4. Springer-Verlag, 2001, p. 199209.

5. Sue, C.; Martinod, P.; Tricart, P.; Thouvenot, F.; Gamond, J-F.; Fréchet, J.; Marinier, D.; Glot, J-P.; Grasso, J-R. Active deformation in the inner Western Alps inferred from comparison between 1972-classical and 1996-GPS geodetic surveys. Tectonophysics, Vol 320, Issue 1. Elsevier Science B. V., 2000, p. 17-29.

6. Gamal, S. El-Fiky. Elastic and inelastic strains in the Japanese Islands deduced from GPS dense array. Earth Planets and Space, Vol 52, No 11. Terra Scientific Publishing Company, 2000, p. 1107-1112.
7. Chang, C-P.; Chang, T-Y.; Angelier, J.; Kao, H.; Lee, J-C.; $\mathrm{Yu}, \mathrm{S}-\mathrm{B}$. Strain and stress field in Taiwan oblique convergent system: constraints from GPS observation and tectonic data. Earth and Planetary Science Letters, Vol 214, Issues 1-2. Elsevier B. V., 2003, p. 115-127.

8. Gamal, S. El-Fiky; Kato, T. Continuous distribution of the horizontal strain in the Tohoku district, Japan, predicted by least-squares collocation. Journal of Geodynamics, Vol 27, Issue 2. Pergamon, 1998, p. 213-236.

9. Atkočiūnas, J.; Nagevičius, J. Foundations of the theory of elasticity (Tamprumo teorijos pagrindai). Vilnius: Technika, 2000. 264 p. (in Lithuanian).

10. Zadro, M.; Braitenberg, C. Measurements and interpretations of tilt-strain gauges in seismically active areas. Earth-Science Reviews, Vol 47, Issues 3-4. Elsevier Science B. V., 1999, p. 151-187.

11. Čyras, A. Structural mechanics (Statybinè mechanika). Vilnius: Mokslas, 1989. 446 p (in Lithuanian).

12. Singiresu, S. Rao. The finite element method in engineering. Third edition. Butterworth-Heinemann, 1999. $556 \mathrm{p}$.

13. Hughes, Thomas J. R. The finite element method: linear static and dynamic finite element analysis. Dover Publications, Inc., 2000. 682 p.

14. Tectonic structure of Lithuania (Lietuvos tektonine sandara). Compiled and edited by P. Suveizdis, Institute of Geology and Geography, Vilnius, 2003. 160 p. (in Lithuanian).

15. Marcinkevičius, V.; Laškovas, J. Tectonic conditions of Ignalina Nuclear Power Plant region (Ignalinos atominès elektrinès rajono tektoninès sąlygos). Geological horizons (Geologijos akiračiai), No 1-2. Vilnius, 1996, p. 8-23 (in Lithuanian).

16. Zakarevičius, A.; Stanionis, A. The features of dispersion of horizontal deformations of the Earth's crust in the region of Ignalina nuclear power plant (Horizontaliujuc Žemès plutos deformaciju Ignalinos atominès elektrinès rajone sklaidos ypatumai). Geodesy and Cartography (Geodezija ir kartografija), Vol XXIX, No 4, Vilnius: Technika, 2003, p. 119-123 (in Lithuanian).

17. Zakarevičius, A.; Aksamitauskas, Č.; Stanionis, A. Horizontal deformations of the Earth's crust in Ignalina nuclear power plant region (Горизонтальные деформации Земной коры в районе Игналинской атомной электростанции). Інженерна геодезія, № 49, КИїВ, 2003, p. 102-110 (in Russian).

18. Petroškevičius, P. Gravitation field effect on geodetic observations (Gravitacijos lauko poveikis geodeziniams matavimams). Vilnius: Technika, 2004. 292 p. (in Lithuanian). 